\title{
FARMERS’ KNOWLEDGE OF FERTILIZERS' PRACTICES ON THEIR FARMS
}

\author{
Talal Saeed HAMEED ${ }^{1}$, Barbara SAWICKA ${ }^{2}$ \\ ${ }^{1}$ Agriculture Extension. \& Technology Transfer Department, College of Agric. \& Forestry, \\ University of Mosul, IRAQ \\ ${ }^{2}$ Department of Plant Production Technology and Commodity Sciences, University of Life Sciences \\ in Lublin, POLAND \\ E-mail of corresponding author: stalal39@yahoo.com
}

Key words: Agriculture Extension, Farmers Knowledge, Fertilizers, Management of fertilization

\begin{abstract}
This study was carried out in Lublin region to identify farmers' knowledge in the use of fertilizers. Data for the study were collected by an interview using a questionnaire of selected sample of 122 farmers to measure farmers' knowledge in the use of fertilizers. The majority $(61.47 \%)$ of farmers were between $32-$ 43 years, the results showed that there were significant differences between the average knowledge of the use of fertilizers according to the variables in the following categories: age, education level, years of work in agriculture. The results of the work will allow farmers and agricultural advisors to make the right decisions that will be beneficial for sustainable agriculture and the environment.
\end{abstract}

\section{INTRODUCTION}

Fertilizers are used to increase crop yields and to replace soil nutrients removed from harvested crops. They have been valuable in reversing the trend of declining soil productivity and soil nutrients. The importance of fertilizer is quite evident for maintaining the fertility of soil and getting an increased production. Natural fertilizers, including manure, slurry and manure, are valuable sources of organic matter and nutrients for plants. The skillful handling of natural fertilizers is important for economic and productivity reasons as it contributes to the improvement of soil fertility and fertility, and it also helps to reduce mineral fertilization. Excess natural fertilizers can, however, be a serious threat to the environment. In order to get the objectives of increasing agricultural production, firstly, it is very important that required quantity of fertilizer is easily available to farming community, and secondly, the recommended dose of fertilizer, is applied at the proper time and dose. Hence, the importance of fertilizers' use rises. Fertilizers are substances containing chemical elements such as nitrogen, phosphorus, potassium, magnesium and other elements that improve the growth of plants. They give nutrition to the crops. When added to soil or water, plants can develop tolerance against harmful organisms, like weeds, insects and diseases. This means that the need for herbicides and insecticides is reduced due to the production of healthier crops. Diseases can also be eliminated, which gives aesthetic value to the harvest. The agricultural extension has important role in this field through the transfer of new information and knowledge about the use of organic fertilizers to farmers and also to the development of information and the capacity of farmers in all the fields of agriculture. (Chauhan 2007, Kuepper 2003). However, most of these nutrient management technologies, programs, and recommendations have not been adopted by farmers (Dan Pan 2014). The primary 
reason for this problem is rooted in the lack of knowledge and information by end users, because the majority of farmers have received limited education about the value and efficient use of plant nutrients (Huang 2008).

Fertilizers help plants to overcome stress situations by increasing their capacity to hold more water and improve the rooting depth. The potassium found in fertilizers is meant to make the stalks and straws of plants stronger. Fertilizers do not only assist in increasing yields and promoting healthy growth of plants, but also in their development.

According to the concept of sustainable development, agricultural production, the aim of which is the production of good quality food, must be carried out in accordance with the requirements of environmental protection. One of them is to minimize the loss of minerals, especially nitrogen and phosphorus, into the aquatic environment. This condition can be fulfilled when the fertilization is well managed, adapted for food needs of plants and soil conditions. You can expect good use of nutrients by plants, which reduces the risk of their losses from agriculture. It also has an economic and social dimension.

\section{MATERIAL AND METHODS}

The study was conducted in Lublin Regions and included 122 farmers. Data were collected through a questionnaire, which consisted of two parts. The first part included the independent variables. Level of education included: (1) a graduate of elementary education, (2) a graduate of secondary education, (3) a graduate of the agricultural Institute, (4) a graduate of college, (5) the highest certificate. Sources of agricultural information has been measured by (10) the sources of agricultural information (Extension agents - Friends and Relatives - Farmers association - Radio - Television - Agricultural Newspapers - Agricultural magazines - Mobile Phones - Internet and others) and alternatives included the following indicators (often, sometimes, and do not use) they were given numeric codes $(1,2,3$ respectively). The second part included the scale farmers' knowledge in the use of fertilizers. One point was given if no knowledge was used. Two points were given if the knowledge was at a low level. Three points were given if the knowledge was at a medium level. Four points were given if the knowledge in the use the fertilizers was at a high scale. Data were collected in the period between June to September 2015. The original data set included 17 paragraphs and the data were measured for validity and quality by a specialist at the Rural Development Department, based on the evaluation processes. Also, 30 questionnaires were excluded after determining the data consistency (total reliability coefficient was 0.89) (Pallant 2005). The frequencies, weighted percentage and Spearman-rank correlations, were used to analyze the data. Data were analyzed using the SPSS program.

\section{RESULTS AND DISCUSSIONS}

\section{Identify level of farmers' knowledge in the use of fertilizers in Lublin District}

The results showed that the highest value of farmers' knowledge in the use of fertilizers were 51 numeric values and the lowest was 22 with an average of (48.41) with a standard 
deviation of (3.33). The growers were divided into three categories according to the level of knowledge in the use of fertilizers. The first category was at the lowest level of their knowledge (22-31), with a mean (20.49\%) and the second category at the application level average ranged between (32-41), with a mean of $(61.47 \%)$. The Third category representing the high application-level (42-51) with a mean of (18.04\%) and this shows that the level of application of the farmers is medium tends to high, as in the table 1.

Table 1. Level of knowledge in use of fertilizers by cultivators in Lublin District

\begin{tabular}{|l|c|c|}
\hline \multicolumn{1}{|c|}{ Categories Level of knowledge } & Frequency & $\%$ \\
\hline Low (22- 31) & 25 & 20.49 \\
\hline Medium (32-41) & 75 & 61.47 \\
\hline High (42-51) & 22 & 18.04 \\
\hline Total & 122 & 100.00 \\
\hline S.D $=3.33$ & & $\mathrm{X}=48.41$
\end{tabular}

Table 2. Rank order of the items of scale to measure Knowledge of Farmers in use of fertilizers

\begin{tabular}{|l|l|c|c|}
\hline No & Items & C.V & Mean \\
\hline 1 & Use the fertilizers depended on crop type & 0.233 & 3.45 \\
\hline 2 & Available nitrogen stored in the soil at planting & 0.239 & 3.39 \\
\hline 3 & Nitrogen released by the soil during the growing season & 0.257 & 3.05 \\
\hline 4 & Need for Sulphur fertilizer determined by a soil test & 0.294 & 2.87 \\
\hline 5 & Soil moisture & 0.305 & 2.78 \\
\hline 6 & Use the fertilizers depended on soil type (clay and organic matter content) & 0.388 & 2.69 \\
\hline 7 & Type of fertilizer & 0.391 & 2.57 \\
\hline 8 & Time of application & 0.399 & 2.52 \\
\hline 9 & Banding fertilizer & 0.411 & 2.49 \\
\hline 10 & Contributes to increased salinity on some soil & 0.424 & 2.33 \\
\hline 11 & Assessment of economic returns from fertilizer & 0.486 & 2.28 \\
\hline 12 & Fertilization as top dressing & 0.511 & 2.21 \\
\hline 13 & Band Fertilization & 0.518 & 2.14 \\
\hline 14 & Over and side application & 0.566 & 2.09 \\
\hline 15 & Spraying onto leaves & 0.574 & 2.01 \\
\hline 16 & Application by irrigation water & 0.581 & 1.94 \\
\hline 17 & Fertilization as Top Dressing & 0.589 & 1.88 \\
\hline
\end{tabular}

\section{Identify the relationship between Farmers' Knowledge about the use of the fertilizers and each of the independent variables}

Age. The results in table (3) indicate that the highest age among the respondents was (55) years and the lowest age among the respondents was (19), The distribution of respondents into categories, found that the percentage of the category (19-31) years was (28.69\%) and the percentage of the category (32-43) years was $(48.36 \%)$, while the percentage of the category (44-55) years was $(22,95 \%)$. The previous results mean that younger farmers were involved in organic farming practices more than older farmers. Spearman correlation coefficient was 0.181 (at 0.05 probability), this agrees with Hameed and Sawicka (2017) for the relationship between the Farmers; Knowledge about the use of the fertilizers and age.

Education Level. The distribution of respondents into categories based on their education level is shown in table 3 . The percentage of graduates of primary and secondary school 
was $(9.83 \%)$ and $(17.21 \%)$, respectively. The percentage of respondents who have a certificate of an Institute and College was (25.41\%) and (38.52\%) respectively the percentage of participants who have the highest certificate was $(9.01 \%)$. The Spearman correlation coefficient was 0.303 (at 0.01 probability) between the Farmers' Knowledge about the use of the fertilizers and education level. This agrees with Chouichom and Yamao (2010).

Type of tenure. The results in table (3) indicate that the percentage of respondents who own land was $(21.32 \%)$ and those who rent the land reached $(27.04 \%)$, while the land contracts was (27.87\%). The percentage of respondents with a type of possession of the land participation were $(23.77 \%)$. The Spearman correlation coefficient was 0.046 between Farmers' Knowledge about the use of the fertilizers and type of tenure the correlation was not significant, this disagree with Chouichom and Yamao (2010), which indicates that this type of acquisition has no effect on Farmers' knowledge.

Years of work in agriculture. Table 3. shows that the percentage of respondents, who have a number of years of work in agriculture between (9-21 years), was (24.60\%) and the percentage of respondents who work for (22-34 years) was $(37.70 \%)$, while the percentage of respondents who work in agriculture for (35-47 years) was (37.70\%). The results show that three-quarters of the respondents were working in agriculture for a long period of time. Spearman correlation coefficient for the Farmers' Knowledge about the use of the fertilizers and years of work in agriculture was 0.170 at ( 0.05 probability). The correlation value here indicates that the increase in the number of years of work in agriculture has a significant impact on the accumulation of experience related to the agricultural practices and may raise their knowledge in using the fertilizers.

Agricultural cultivated area. Table 3. shows, that the highest percentage of respondents who have an area of land between (12-36) ha was (31.15\%) and the percentage of respondents who have an area of land between (37-61) ha was (40.16\%), while the percentage of respondents who have an area of land between (62-86) ha was (28.69\%). The Spearman correlation coefficient between Farmers' Knowledge about the use of the fertilizers and Agriculture cultivated land was not significant (0.057).

Agricultural information sources. The results presented in table 3. expressed that the highest numeric value to agricultural information sources was 30 and the lowest value was 10. The distribution of the respondents according to the categories of sources of agricultural information showing that the respondents who fall within the low category were making the highest percentage $(42.63 \%)$, while the percentage of farmers in the category of medium level were $(33.60 \%)$ and the percentage of high-level reached $(23.77 \%)$. To find the relationship between the Farmers' Knowledge about the use of the fertilizers and agricultural information sources correlation coefficient of Spearman was used and it was not significant (0.087). This disagrees with Oyesola and Obabire (2011) and Oluwasusi (2014). Such an insignificant value might be due to the insufficient information that were provided for the farmers regarding another aspect. 
Table 3. The correlation between some variables and level of application cultivators

\begin{tabular}{|c|c|c|c|c|}
\hline The significance & Rs Value & $\%$ & Frequency & The variables \\
\hline \multicolumn{5}{|c|}{ Age } \\
\hline \multirow{3}{*}{$*$} & \multirow{3}{*}{0.181} & 28.69 & 35 & Year (31-19) \\
\hline & & 48.36 & 59 & Year $(43-32)$ \\
\hline & & 22.95 & 28 & Year $(55-44)$ \\
\hline \multicolumn{5}{|c|}{ Education Level } \\
\hline \multirow{5}{*}{$* *$} & & 9.83 & 12 & Primary school \\
\hline & & 17.21 & 21 & Secondary school \\
\hline & & 25.41 & 31 & Institute \\
\hline & & 38.52 & 47 & College \\
\hline & & 9.01 & 11 & High certificate \\
\hline \multicolumn{5}{|c|}{ Type of tenure } \\
\hline \multirow{4}{*}{ Not significant } & \multirow{4}{*}{0,046} & 21.32 & 26 & Owned \\
\hline & & 27.04 & 33 & Rented \\
\hline & & 27.87 & 34 & Contract \\
\hline & & 23.77 & 29 & Participation \\
\hline \multicolumn{5}{|c|}{ Years of work in agriculture } \\
\hline \multirow{3}{*}{$*$} & \multirow{3}{*}{0.170} & 24.60 & 30 & year $(21-9)$ \\
\hline & & 37.70 & 46 & year (34-22) \\
\hline & & 37.70 & 46 & year (47-35) \\
\hline \multicolumn{5}{|c|}{ Agricultural cultivated area } \\
\hline \multirow{3}{*}{ Not significant } & \multirow{3}{*}{0.057} & 31.15 & 38 & ha (36-12) \\
\hline & & 40.16 & 49 & ha $(61-37)$ \\
\hline & & 28.69 & 35 & ha $(86-62)$ \\
\hline \multicolumn{5}{|c|}{ Agricultural information sources } \\
\hline \multirow{3}{*}{ Not significant } & \multirow{3}{*}{0.087} & 42.63 & 52 & Low (16-10) \\
\hline & & 33.60 & 41 & Medium (23-17) \\
\hline & & 23.77 & 29 & High (30-24) \\
\hline
\end{tabular}

* Indicates that the value of morale at the level $(0.05)$

** Indicates that the value of morale at the level $(0.01)$

\section{CONCLUSION}

The level of farmers' knowledge about the use of the fertilizers in Lublin province is medium. The variables such as: Agricultural information sources, Agricultural cultivated area, Type of tenure, do not have a clear role in the development of the cognitive level of farmers about the use of the fertilizers. While, the variables such as: (age, education level, size of farm, average yields) play a significant role in the development of the cognitive level of farmers about the use of the fertilizers. The results presented in this paper will help farmers and agricultural advisers to make rational decisions, which will benefit the sustainable agriculture and the environment.

\section{REFERENCES}

Chauhan J. (2007). Agricultural extension education, communication in agriculture, Raja Balwant Singh College, India 14-16.

Chouichom S., Yamao M. (2010). Comparing Opinions and Attitudes of Organic and Non-Organic Farmers Towards Organic Rice Farming System in North-Eastern Thailand. Journal of Organic Systems, 5(1), 25-35. ISSN: 1177-4258.

Dan Pan. (2014). The Impact of Agricultural Extension on Farmer Nutrient Management Behavior in Chinese Rice Production: A Household-Level Analysis. Sustainability 6, 6644-6665.

Hameed T.S., Sawicka B. (2017). Production and Marketing Problems of Potato Growers. International Journal of Current Research 9(5), 49729-49732. 
Huang J., Hu R., Cao, J., Rozelle, S. (2008). Training programs and in-the-field guidance to reduce China's overuse of fertilizer without hurting profitability. J. Soil Water Conserv. 2008, 63, 165-167.

Kuepper G. (2003). Manures for organic crop production, soil systems guides oil Systems guide. Approach Technology Transfer for Rural Areas (ATTAR), USA, 3-9.

Oyesola O.B., Obabire I.E.B. (2011). Farmers' perceptions of organic farming in selected local government areas of Ekiti State, Nigeria. Journal of Organic Systems 6(1), ISSN: 1177-4258, 20-26.

Pallant J. (2005). SPSS survival manual a step by step guide to data analysis using SPSS for Windows (Version 12), 130-132. 